\title{
Application of ICG-enhanced thermocoagulation method and photodynamic therapy in circumscribed choroidal hemangioma
}

\author{
CHUAN TIAN, XI CHEN, JIN CAO and LU YANG \\ Department of Ophthalmology, The Affiliated Hospital of Medical College \\ of Ningbo University, Jiangbei, Ningbo, Zhejiang 315020, P.R. China
}

Received September 14, 2017; Accepted January 19, 2018

DOI: $10.3892 / 01.2018 .8056$

\begin{abstract}
The present study was designed to compare the effect of indocyanine green (ICG)-enhanced laser $(810 \mathrm{~nm})$ thermocoagulation method and photodynamic therapy (PDT) on circumscribed choroidal hemangioma $(\mathrm{CCH})$. A total of 36 patients (36 pair of eyes) diagnosed with $\mathrm{CCH}$ in the Ocular Fundus Disease Center of The Affiliated Hospital of Medical College of Ningbo University from June 2010 to January 2016 were selected and randomly divided into two groups. ICG-enhanced thermocoagulation was used to treat 18 patients (18 pair of eyes), and PDT was used to treat the remaining 18 patients (18 pair of eyes). The best corrected visual acuity of the affected eyes was observed before and after treatment, and changes in the tumor were observed through ocular fundus photochromes under the ophthalmoscope. The changes in tumor size and height were examined through B-scan ultrasonography. The changes in serous retinal fluid were examined by optical coherence tomography (OCT). A total of 36 patients were followed-up for 3, 7, 11 and 24 weeks after laser therapy with an average of 18 weeks. It was seen that the subretinal serous exudation disappeared in 36 patients through the fundus examination after treatment, and B-scan ultrasonography showed that the tumor size was reduced. Among 18 patients undergoing ICG-enhanced thermocoagulation treatment, the visual acuity of $72.2 \%$ of them was improved, while that of the remaining $27.8 \%$ was stable, and there were no patients with decreased visual acuity; the fundus observation showed that when tumor atrophy occurred, the tumor turned white accompanied with mild pigment disorders, but retinal and choroidal normal vessels were not damaged. Among 18 patients undergoing PDT treat-
\end{abstract}

Correspondence to: Dr Lu Yang, Department of Ophthalmology, The Affiliated Hospital of Medical College of Ningbo University, 247 Renmin Road, Jiangbei, Ningbo, Zhejiang 315020, P.R. China E-mail: lu_yang02@163.com; yanglu@nbu.edu.cn

Key words: choroidal neoplasms, hemangioma, indocyanine green, circumscribed choroidal hemangioma, photocoagulation method ment, the visual acuity of $44.4 \%$ was increased, that of $50 \%$ was stable, and that of $5.6 \%$ of the patients was decreased; through fundus observation, tumor atrophy scars and alignment, a large number of hyperplasia or pigment loss and partial vascular occlusion could be seen. The results indicated that in the treatment of CCH, ICG-enhanced laser $(810 \mathrm{~nm})$ thermocoagulation and PDT can lead to tumor atrophy and promote the absorption of exudation. However, the damage of ICG-enhanced laser thermocoagulation to normal fundus tissues is significantly smaller than that of PDT, and the former has higher safety.

\section{Introduction}

Choroidal hemangioma $(\mathrm{CH})$ is a benign vascular tumor, whose main cause is congenital vascular dysplasia, and it is rarely seen clinically. According to its clinical manifestations, it can be divided into circumcisioned choroidal hemangioma $(\mathrm{CCH})$ and diffuse choroidal hemangioma (1-4). CCH mostly occurs in one eye, and its onset age span is large, ranging from 11 to 70 years according to reports, but mainly distributed in the age range from 30 to 40 years, and it is rarely seen in the population aged below 20 (5-8). The progression of $\mathrm{CCH}$ is slow, but with the prolonged course of the disease, the tumor size is gradually increased, leakage occurs and retinal pigment epithelial degeneration appears, so the barrier effect is lost, causing serous retinal detachment and macular edema $(3,9,10)$. Natural course of the disease often comes to an end with secondary glaucoma causing pain and blindness, and the natural prognosis is poor $(11,12)$. There are a variety of clinical $\mathrm{CCH}$ treatments, in which photodynamic therapy (PDT) is the main means for the treatment of $\mathrm{CCH}$ presently (13-15). Indocyanine green (ICG) has been used as a contrast agent for fundus angiography for more than 10 years. It has many characteristics, the most important of which is that its absorption peak $(805 \mathrm{~nm})$ is similar to the laser wavelength of semiconductor $(810 \mathrm{~nm})$, and its operation is simple, which provides a basis for the clinical application of ICG as a photosensitizer. In the present study, the effects of ICG-enhanced laser $(810 \mathrm{~nm})$ thermocoagulation method and PDT in the treatment of $\mathrm{CCH}$ were compared so as to explore the clinical value of the two methods. 
Table I. General data.

\begin{tabular}{|c|c|c|c|}
\hline Item & $\begin{array}{l}\text { ICG-enhanced laser }(810 \mathrm{~nm}) \\
\text { thermocoagulation group }(\mathrm{n}=18)\end{array}$ & $\begin{array}{l}\text { PDT treatment } \\
\text { group }(n=18)\end{array}$ & P-value \\
\hline Affected eye (left/right) & $8 / 10$ & $9 / 9$ & $0.14^{\mathrm{a}}$ \\
\hline Sex (male/female) & $10 / 8$ & $9 / 9$ & $0.15^{\mathrm{a}}$ \\
\hline Average age (years) & $56 \pm 6.23$ & $53 \pm 5.4$ & $0.21^{\mathrm{b}}$ \\
\hline Diameter of tumor (mm) & $9.76 \pm 1.17$ & $9.81 \pm 1.21$ & $0.13^{\mathrm{b}}$ \\
\hline Thickness of tumor (mm) & $3.51 \pm 0.18$ & $3.55 \pm 0.17$ & $0.11^{\mathrm{b}}$ \\
\hline Median of the BCVA & 0.35 & 0.30 & $1^{\mathrm{c}}$ \\
\hline $\begin{array}{l}\text { Tumor site (optic papilla-adjacent/macula lutea- } \\
\text { adjacent/under the macula lutea) }\end{array}$ & $5 / 6 / 7$ & $6 / 6 / 6$ & $0.09^{\mathrm{a}}$ \\
\hline Subretinal fluid $(+/++/+++)$ & $4 / 13 / 1$ & $5 / 12 / 1$ & $0.32^{\mathrm{a}}$ \\
\hline Course of the disease & $5.32 \pm 0.48$ & $5.26 \pm 0.51$ & $0.24^{\mathrm{b}}$ \\
\hline
\end{tabular}

${ }^{\mathrm{a} C h i}$-aquare test; ${ }^{\mathrm{b} t \text {-test; }}{ }^{\mathrm{n}}$ non-parametric test; $\mathrm{P}>0.05$, differences in the general data of two groups of patients are not statistically significant. ICG, indocyanine green; PDT, photodynamic therapy; BCVA, best corrected visual acuity.

\section{Patients and methods}

General condition. The patients treated in the Ocular Fundus Disease Center of The Affiliated Hospital of Medical College of Ningbo University (Zhejiang, China) from June 2010 to January 2016 were selected. They were diagnosed with $\mathrm{CCH}$, which was confirmed by slit lamp examination, 90D frontoscopy examination, ophthalmology B-scan ultrasonography, optical coherence tomography (OCT), fundus fluorescence angiography (FFA), and indocyanine green angiography (ICGA).

Inclusion criteria: i) Patients with decreased visual acuity, metamorphopsia or other clinical complaints; ii) with serous retinal detachment, macular edema or other complications; iii) patients who had subjective desire for receiving treatments; iv) with clear refractive media (not affecting the laser treatment and follow-up observation); and v) patients not undergoing PDT or other surgical treatments before the diagnosis of the disease. Exclusion criteria: i) Patients with no clinical complaints; ii) with no serous retinal detachment, macular edema or other complications; iii) having no subjective desire for receiving treatments; and iv) whose general conditions were not suitable for receiving FFA/ICGA examination or laser treatments.

The study was approved by the Ethics Committee of The Affiliated Hospital of Medical College of Ningbo University (Zhejiang, China) and informed consents were signed by the patients and/or guardians.

A total of 36 patients (36 pair of eyes) with $\mathrm{CCH}$ were eligible for the above criteria, including 19 males and 17 females. Their age at evaluation was 45-57 years. The best corrected visual acuity (BCVA) was hand motion (HM) $/ 20 \mathrm{~cm}-0.6$ before treatment. Tumor local situation: $\mathrm{CCH}$ was located in the posterior fundus in 36 patients (in the right eye of 19 patients and the left of 17 patients). Among them, the tumor was located 1/2-1PD adjacent to the optic papillas in 11 patients (5 patients in the ICG and 6 in the PDT group), located in the central fovea of macula luteae in 12 patients (6 in the ICG and 6 in the PDT group), and located under the central fovea of macula luteae in 13 patients ( 7 in the ICG and 6 in the PDT group). Before treatment, B-scan ultrasonography showed that the largest base diameter was 7.0-11.6 $\mathrm{mm}$ with the average value of $8.7 \mathrm{~mm}$; the maximum tumor thickness was 2.4-5.0 $\mathrm{mm}$ with the average value of $3.53 \mathrm{~mm}$. A total of 36 patients were associated with serous retinal detachment in the macular region. Detailed comparisons of general data between two groups of patients are shown in Table I.

Treatment methods. In the ICG-enhanced laser thermocoagulation group, the tumor was irradiated with isotope ratio infrared spectrometer semiconductor laser $(810 \mathrm{~nm})$ (Oculight SLx; Iridex Corp., Mountain View, CA, USA); the preset diameter of macula luteae was $3 \mathrm{~mm}$, laser energy was $640 \mathrm{~mW}$, irradiation time was $90 \mathrm{sec}$, and the magnification of the ophthalmoscope was 1.0. After the instrument and the patient were ready for the treatment, $50 \mathrm{mg} / 5 \mathrm{ml} \mathrm{ICG} \mathrm{was}$ injected through the opisthenar veins. Two minutes later, the irradiation site was selected from the tumor area away from the macula lutea or the optic disc, and then the tumor area near the optic disc or the central fovea was irradiated. Finally, the tumor area involved in the central fovea was irradiated. A number of macula luteae completely covered the entire tumor. Laser irradiation was conducted until the surface of tumor just became greyish white, and then the treatment was immediately terminated (if the desired response of tumor was not seen at $90 \mathrm{sec}$ after the treatment process, the irradiation time should be appropriately extended until the expected photocatalytic reaction appeared).

In the PDT treatment group, the phenylpropanone porphyrin derivative, photoacid photosensitizer was used, and the dose was calculated according to the body surface area $\left(6 \mathrm{mg} / \mathrm{m}^{2}\right)$. The intravenous injection was finished within $10 \mathrm{~min}$. At $5 \mathrm{~min}$ after intravenous injection, the laser irradiation (wavelength was set to $689 \mathrm{~nm}$ ) was conducted, the diameter of macula luteae was $2.1-5.3 \mathrm{~mm}$, and the radiated macula luteae fully covering the tumor was regarded as the best radiation. If a single macula lutea could not fully cover the tumor lesions, the number of it could be increased to complete the irradiation. When the tumor thickness was less than $3.0 \mathrm{~mm}$, the exposure time was set to $83 \mathrm{sec}$; when the tumor 
Table II. Changes in BCVA and subretinal fluid of patients before and after treatment.

\begin{tabular}{|c|c|c|c|c|}
\hline \multirow[b]{2}{*}{ Treatment grouping } & \multicolumn{2}{|c|}{ BCVA } & \multicolumn{2}{|c|}{ Subretinal fluid } \\
\hline & Before treatment & After treatment & Before treatment & After treatment \\
\hline \multirow[t]{19}{*}{$\operatorname{PDT}(\mathrm{n}=18)$} & 0.2 & 0.5 & + & - \\
\hline & 0.25 & 0.35 & ++ & - \\
\hline & 0.3 & 0.6 & + & - \\
\hline & $\mathrm{CF} / 10 \mathrm{~cm}$ & $\mathrm{CF} / 10 \mathrm{~cm}$ & ++ & - \\
\hline & $\mathrm{HM} / 20 \mathrm{~cm}$ & $\mathrm{HM} / 10 \mathrm{~cm}$ & ++ & - \\
\hline & 0.4 & 0.6 & ++ & - \\
\hline & 0.04 & $\mathrm{CF} / 30 \mathrm{~cm}$ & ++ & - \\
\hline & 0.3 & 0.35 & + & - \\
\hline & 0.7 & 1.0 & ++ & - \\
\hline & 0.5 & 1.0 & ++ & - \\
\hline & 0.3 & 0.6 & +++ & - \\
\hline & 0.1 & 0.25 & + & - \\
\hline & 0.8 & 1.0 & ++ & - \\
\hline & 0.7 & 1.0 & ++ & - \\
\hline & 0.25 & 0.4 & ++ & - \\
\hline & 0.8 & 0.5 & ++ & - \\
\hline & 0.3 & 0.35 & ++ & - \\
\hline & 0.2 & 0.25 & + & - \\
\hline & 0.35 & 0.5 & ++ & - \\
\hline \multirow[t]{17}{*}{ ICG $(n=18)$} & 0.4 & 0.7 & ++ & - \\
\hline & 0.5 & 1.0 & ++ & - \\
\hline & 0.2 & 0.4 & ++ & - \\
\hline & 0.6 & 0.8 & ++ & - \\
\hline & 0.25 & 0.2 & + & - \\
\hline & 0.25 & 0.7 & ++ & - \\
\hline & 0.15 & 0.5 & +++ & - \\
\hline & 0.8 & 1.0 & ++ & - \\
\hline & 0.4 & 0.8 & ++ & - \\
\hline & 0.25 & 0.25 & + & - \\
\hline & 0.5 & 1.0 & ++ & - \\
\hline & 0.3 & 0.6 & ++ & - \\
\hline & 0.4 & 0.8 & ++ & - \\
\hline & 0.6 & 1.0 & ++ & - \\
\hline & 0.3 & 0.6 & ++ & - \\
\hline & 0.25 & 0.3 & + & - \\
\hline & 0.4 & 0.4 & + & - \\
\hline
\end{tabular}

$\mathrm{CF}$, counting figures; HM, hand motion; LP, light perception; NLP, no light perception; BCVA, best corrected visual acuity; PDT, photodynamic therapy; ICG, indocyanine green; OCT, optical coherence tomography. Volume of subretinal fluid: The height of subretinal fluid is detected by OCT, and the tumor area is detected by radiography.

thickness was greater than $3.0 \mathrm{~mm}$, the exposure time was set to $124 \mathrm{sec}$, and patients were treated in a dark place for $48 \mathrm{~h}$.

Evaluative criteria for efficacy. Remarkably effective: B-scan ultrasonography showed that the tumor thickness was obviously decreased; ICGA revealed that the occlusion and regression of choroidal small blood vessels in the tumor was blocked, and vascular leakage was alleviated or stopped; OCT examination showed that, the subretinal fluid was reduced or completely absorbed, and the visual acuity (two or more lines) was improved.

Improved: i) B-scan ultrasonography showed that the tumor thickness was reduced; ii) ICGA revealed that tumor vascular leakage was alleviated; and iii) OCT examination showed that the subretinal fluid was reduced, and the visual acuity remained stable (less than 2 lines).

Ineffective: i) B-scan ultrasonography showed that there was no change in the tumor size; ii) ICGA revealed that there 
Table III. Changes in BCVA and subretinal fluid of patients before and after treatment.

\begin{tabular}{lcccc} 
Treatment method & Improved BCVA & Stable BCVA & Decreased BCVA & $\begin{array}{c}\text { Disappeared } \\
\text { subretinal fluid }\end{array}$ \\
\hline PDT (n/\%) & $8 / 44.4 \%$ & $9 / 50 \%$ & $1 / 5.6 \%$ & $18 / 100 \%$ \\
ICG (n/\%) & $13 / 72.2 \%$ & $5 / 27.8 \%$ & $0 / 0 \%$ & $18 / 100 \%$
\end{tabular}

After treatment, the improvement status of the ICG group is better than that of the PDT group. BCVA, best corrected visual acuity; PDT, photodynamic therapy; ICG, indocyanine green.

Table IV. Changes in the fundi of patients after treatment.

\begin{tabular}{|c|c|c|c|c|c|c|}
\hline $\begin{array}{l}\text { Treatment } \\
\text { method }\end{array}$ & $\begin{array}{l}\text { Tumor } \\
\text { change }\end{array}$ & $\begin{array}{c}\text { Leakage of } \\
\text { contrast agents }\end{array}$ & $\begin{array}{l}\text { Pigment } \\
\text { changes }\end{array}$ & $\begin{array}{l}\text { Alignment } \\
\text { and scars }\end{array}$ & $\begin{array}{l}\text { Hemorrhage in the } \\
\text { treatment region }\end{array}$ & $\begin{array}{c}\text { Normal blood } \\
\text { vessel injury }\end{array}$ \\
\hline PDT & Atrophy & Alleviated & Obvious hyperplasia & + & $+(n)$ & + \\
\hline ICG & Atrophy & Alleviated & Slight disorder & - & - & - \\
\hline
\end{tabular}

ICG is superior to PDT in side effects and complications after treatment. ICG, indocyanine green; PDT, photodynamic therapy.

Table V. Change of tumor size before and after treatment.

\begin{tabular}{|c|c|c|c|c|c|}
\hline \multirow[b]{2}{*}{ Observation index } & \multicolumn{2}{|c|}{ ICG group } & \multicolumn{2}{|c|}{ PDT group } & \multirow[b]{2}{*}{ P-value } \\
\hline & Before treatment & After treatment & Before treatment & After treatment & \\
\hline Diameter of tumor & $9.76 \pm 1.17$ & $4.45 \pm 1.05$ & $9.81 \pm 1.21$ & $5.03 \pm 1.12$ & 0.003 \\
\hline Thickness of tumor & $3.51 \pm 0.18$ & $1.25 \pm 0.09$ & $3.55 \pm 0.17$ & $1.81 \pm 0.12$ & 0.002 \\
\hline
\end{tabular}

There are no statistically significant differences in the tumor diameter and thickness between the ICG group and the PDT group before treat-

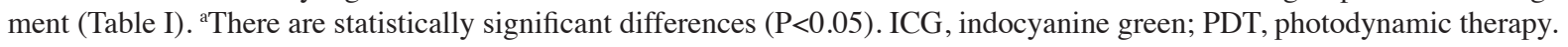

was no occlusion or regression of choroidal small blood vessels in the tumor, and blood vessels continued to leak; and iii) OCT examination showed that the subretinal fluid was not subsided or increased, and the visual acuity continued to decline.

Follow-up. The patients were followed-up for 3, 7, 11 and 24 weeks after laser therapy. The changes in the BCVA, tumor size and subretinal fluid, and leakage status of tumor during the fluorescein angiography and ICGA were observed before and after treatment. All the patients were treated once, and further treatment could be conducted according to the medical necessities of patients at the end of follow-up.

Statistical analysis. SPSS 20.0 software (IBM Corp., Armonk, NY, USA) was applied, and Chi-square test was used for comparisons of enumeration data. Measurement data were expressed as mean $\pm \mathrm{SD}$, and the independent-samples t-test was used for intergroup comparisons of data conforming to the normal distribution, while the non-parametric KolmogorovSmirnov (KS) test was used for data not conforming to it. Statistically significant difference was set at $\mathrm{P}<0.05$.

\section{Results}

Visual acuity. With the standard logarithmic visual acuity letter chart as the criteria, two or more lines advanced on the chart after treatment represented that the visual acuity was improved; less than two lines advanced on the chart represented that the visual acuity remained stable after treatment; more than one line descended on the chart after treatment represented that the visual acuity was decreased. Before treatment, the BCVA of 36 patients was $\mathrm{HM} / 20 \mathrm{~cm}-0.6$. After treatment, among 18 patients treated with ICG-enhanced thermocoagulation, the visual acuity of $72.2 \%$ was improved, that of $27.8 \%$ remained stable, and there were no patients with decreased visual acuity. After treatment, among 18 patients undergoing PDT treatment, the visual acuity of $44.4 \%$ was increased, that of $50 \%$ was stable, and that of $5.6 \%$ of the patients was decreased (Tables II and III).

Subretinal fluid. OCT showed that before treatment, 36 patients were associated with macular subretinal fluid at varying degrees, and 9 patients were combined with macular cystoid edema. During the period from the end of the treatment 


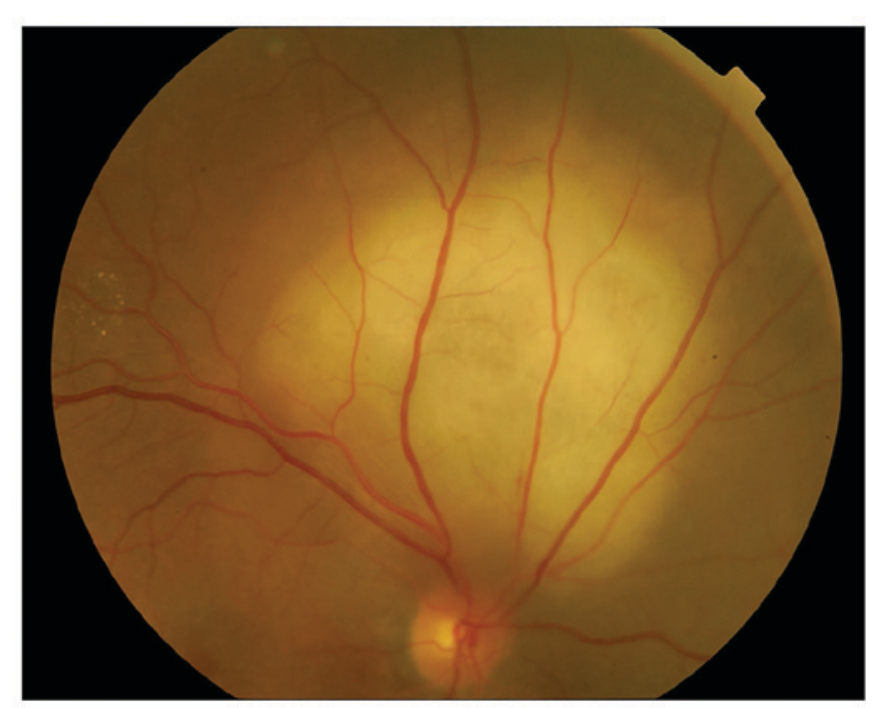

Figure 1. Ocular fundus photochromes of a patient in the ICG group before treatment. ICG, indocyanine green.

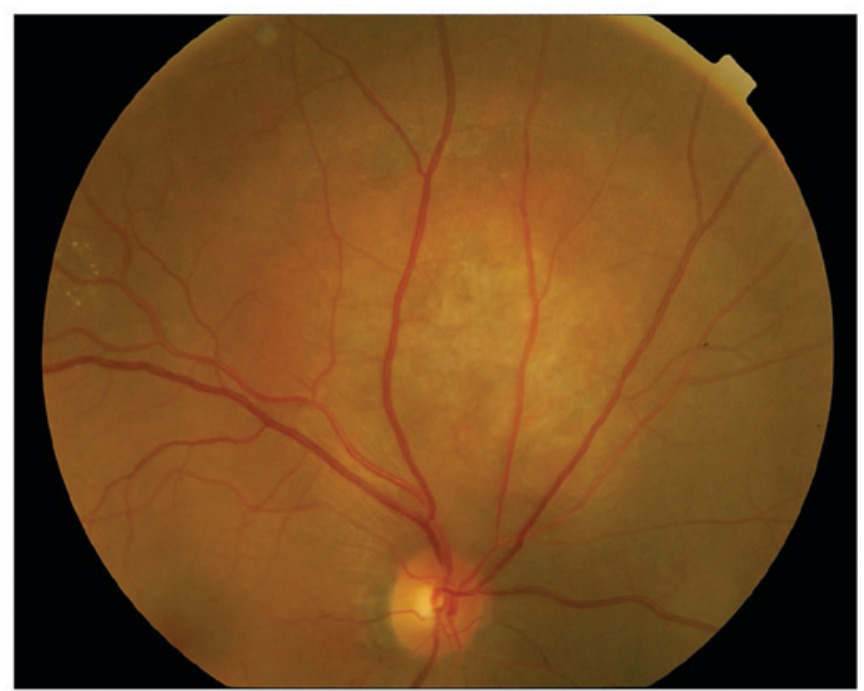

Figure 2. Ocular fundus photochromes of a patient in the ICG group at 11 weeks after treatment. ICG, indocyanine green.

to the last follow-up, the subretinal fluid of 36 patients was completely absorbed, and their retinas were not detached (Tables II and III).

Ocular fundus changes. Before treatment, the full mydriasis examination was conducted for the fundi of 36 patients, which showed that the tumor was swollen in the jacinth round or oval shape. Tumors were mostly located in the area adjacent to macula luteae or optic papilla, and there was an unclear boundary between them and the surrounding normal retinas. The tumor surface and the surrounding serous retinas were detached, and involved the macula luteae, and the proliferation of a small amount of pigments could be seen in the tumor surface of some patients (Figs. 1 and 2). At half an hour after treatment, the reactive edema appeared in the treatment area, which turned into grayish white and gradually became milky white or porcelain white by the 2 nd day. At the last follow-up, tumors of 36 patients were atrophied and flattened, and the atrophy of choroid membranes and different degrees of retinal pigment proliferation could be observed. Among them, vascular occlusion could be seen on the tumor surface of one patient receiving PDT treatment, which was accompanied with a small splinter hemorrhage in the shallow of retinas in the distal blood supply region (Table IV).

Tumor size. Tumors of 36 patients after treatment were smaller than those before treatment to different degrees. The differences in the tumor diameter and thickness between the ICG and the PDT treatment group were statistically significant, and the efficacy of the ICG was better than that of the PDT treatment group (Table V).

\section{Discussion}

Previously, most people believed that there is no special therapy for $\mathrm{CCH}$. If the secondary glaucoma occurs in the late phase causing pain, enucleation will be conducted. Scleral electrocoagulation, cryopreservation, microwave hyperthermia, external radiotherapy or Co80 radiotherapy have also been used in the treatment of $\mathrm{CCH}$, but due to the relatively larger damage area during the treatment, more postoperative complications and greater side effects, they are now basically eliminated. With the introduction of laser into the field of ophthalmology, laser photocoagulation, transpupillary thermotherapy, PDT and other treatments for $\mathrm{CCH}$ have appeared. However, the cost for PDT is high and its operation is complex, so at present, a safe, effective and economical treatment for $\mathrm{CCH}$ remains to be explored. In 2001, Costa et al (16) conducted an animal experiment for the first time, and ICG-induced laser treatment was performed from the rabbit choroidal capillary layer. The results suggested that ICG can be used as a weak photosensitizer for choroidal neovascularisation therapy. Further studies of Navajas et al (17) and Arevalo et al $(18,19)$ revealed that ICG can be used as a weak photosensitizer in the clinical treatment of cataracts and some other ophthalmic diseases. However, there are relatively fewer studies on ICC treatment of $\mathrm{CCH}$. In the present study, the ICG treatment of $\mathrm{CCH}$ was compared with the commonly used PDT, which confirmed the efficacy and safety of ICG treatment.

The theoretical bases of ICG-enhanced laser $(810 \mathrm{~nm})$ thermocoagulation therapy in the treatment of $\mathrm{CCH}$ are photodynamic and subliminal thermal effects. Costa et al (16) argued that photosensitizer molecules convert energy into heat to damage vascular endothelial cells after laser irradiation, which leads to the accumulation of endothelial cells so as to form thrombosis, thus blocking blood vessels and contributing to the achievement of therapeutic goals. The results of laser photocoagulation in clinical and experimental studies showed that the influence range of argon laser is only $0.2-1.0 \mathrm{~mm}$ on the surface of the tumor (20). Using an infrared laser with the wavelength of $810 \mathrm{~nm}$ can increase the penetration and lethality to the tumor (21), which leads to tumor atrophy and pacification. The results of the present study revealed that the tumor diameter and thickness of $\mathrm{CCH}$ of 18 patients were significantly smaller after the ICG-enhanced laser $(810 \mathrm{~nm})$ thermocoagulation 
therapy than those before the therapy. Clinical data showed that the effective rate of laser photocoagulation treatment for $\mathrm{CCH}$ is only $60 \%$ (22). The results of the present study showed that 18 patients with $\mathrm{CCH}$ receiving $\mathrm{ICG}$-enhanced laser $(810 \mathrm{~nm})$ thermocoagulation therapy were significantly improved, which may be because the selected laser $(810 \mathrm{~nm})$ in this study could kill and wound the tumor to a largest degree. ICG-enhanced thermocoagulation therapy may be the result of a combination of photodynamic and thermal effects, which may still cause damage to the normal retinal tissues of $\mathrm{CCH}$ during the course of treatment. However, in the present study, no obvious complications occurred in 18 patients undergoing ICG-enhanced thermocoagulation therapy, which might be associated with the shortcoming of this study, namely, the small sample size. Due to the limited number of cases and short follow-up time, specific treatment parameters, long-term efficacy and complications need a long-term clinical observation with a larger sample size.

It was found in the present study that relatively better efficacies were achieved after 36 patients in the two groups received different treatments, but the efficacy of the ICG treatment group was better than that of the PDT treatment group. ICG-enhanced thermocoagulation therapy was superior to PDT in improving visual acuity, fundi and the tumor. In addition, with people's pursuit of high quality of life, efficacy, safety and convenience draw more and more attention. ICG is a weak photosensitizer, so there is no need for strict light protection measures after the ICG-enhanced thermocoagulation therapy, which simplifies the treatment process. Besides, the cost for ICG is low, so the promotion of ICG-enhanced thermocoagulation therapy will produce huge economic and social benefits.

In summary, compared with PDT treatment, ICO-enhanced laser $(810 \mathrm{~nm})$ thermocoagulation therapy is simple, inexpensive, safe and effective. If the therapy can be carried out in central and western China, especially in economically underdeveloped areas, it will create enormous economic and social benefits.

\section{Acknowledgements}

Not applicale.

\section{Funding}

No funding was received.

\section{Availability of data and materials}

The datasets used and/or analyzed during the present study are available from the corresponding author on reasonable request.

\section{Authors' contributions}

CT was mainly responsible for the implementation of laser treatment and the writing of the manuscript. JC was responsible for the collection of the data and the follow-up management of the patients. XC was responsible for the statistical analysis of the data. LY helped with the conception and design, as well as revised and finalized the whole manuscript. All authors read and approved the final manuscript.

\section{Ethics approval and consent to participate}

The study was approved by the Ethics Committee of the Affiliated Hospital of Medical College of Ningbo University. (Zhejiang, China). Signed written informed consents were obtained from the patients and/or guardians.

\section{Consent for publication}

Not applicable.

\section{Competing interests}

The authors declare that they have no competing interests.

\section{References}

1. Gan NY, Zimmer C and Lam WC: Multi-spectral imaging of circumscribed choroidal hemangioma introduction. Ophthalmic Surg Lasers Imaging Retina 48: 572-575, 2017 (In English and Spanish).

2. Subirà O, Brosa H, Lorenzo-Parra D, Arias-Barquet L, Català-Mora J, Cobos E, Garcia-Bru P, Rubio-Caso MJ and Caminal-Mitjana JM: Choroidal haemangioma and photodynamic therapy. Anatomical and functional response of patients with choroidal hemangioma treated with photodynamic therapy. Arch Soc Esp Oftalmol 92: 257-264, 2017.

3. Tsipursky MS, Golchet PR and Jampol LM: Photodynamic therapy of choroidal hemangioma in sturge-weber syndrome, with a review of treatments for diffuse and circumscribed choroidal hemangiomas. Surv Ophthalmol 56: 68-85, 2011.

4. Karimi S, Nourinia R and Mashayekhi A: Circumscribed choroidal hemangioma. J Ophthalmic Vis Res 10: 320-328, 2015.

5. Elizalde J, Vasquez L, Iyo F and Abengoechea S: Photodynamic therapy in the management of circumscribed choroidal hemangioma. Can J Ophthalmol 47: 16-20, 2012.

6. Zhang Y, Liu W, Fang Y, Qian J, Xu G, Wang W, Li L, Shen Y and Gao Q: Photodynamic therapy for symptomatic circumscribed macular choroidal hemangioma in Chinese patients. Am J Ophthalmol 150: 710-715, 2010.

7. Blasi MA, Tiberti AC, Scupola A, Balestrazzi A, Colangelo E, Valente $\mathrm{P}$ and Balestrazzi E: Photodynamic therapy with verteporfin for symptomatic circumscribed choroidal hemangioma: Five-year outcomes. Ophthalmology 117: 1630-1637, 2010.

8. Furuta M, Sekiryu T, Kasai A and Oguchi Y: Morphologic changes of the fovea and visual acuity associated with retinal detachment secondary to circumscribed choroidal hemangioma. Saudi J Ophthalmol 27: 209-213, 2013.

9. Ramasubramanian A, Shields CL, Harmon SA and Shields JA: Autofluorescence of choroidal hemangioma in 34 consecutive eyes. Retina 30: 16-22, 2010.

10. Gambrelle J, Graswill C, Mauget-Faysse M, Kodjikian L, Cochener B and Grange JD: Treatment of circumscribed choroidal haemangiomas by photodynamic therapy: A review. J Fr Ophtalmol 33: 497-504, 2010 (In French).

11. Berry $M$ and Lucas LJ: Circumscribed choroidal hemangioma: A case report and literature review. J Optom 10: 79-83, 2017.

12. Zeisberg A, Seibel I, Cordini D, Lakotka N, Willerding G, Moser L, Heufelder J and Joussen AM: Long-term (4 years) results of choroidal hemangioma treated with proton beam irradiation. Graefes Arch Clin Exp Ophthalmol 252: 1165-1170, 2014.

13. Vicuna-Kojchen J, Banin E, Averbukh E, Barzel I, Shulman M, Hemo I, Pe'er J and Chowers I: Application of the standard photodynamic treatment protocol for symptomatic circumscribed choroidal hemangioma. Ophthalmologica 220: 351-355, 2006.

14. Yang CS, Chen KC, Lee SM and Lee FL: Photodynamic therapy in the treatment of choroidal neovascularization complicating central serous chorioretinopathy. J Chin Med Assoc 72: 501-505, 2009. 
15. Boixadera A, García-Arumí J, Martínez-Castillo V, Encinas JL, Elizalde J, Blanco-Mateos G, Caminal J, Capeans C, Armada F, Navea A and Olea JL: Prospective clinical trial evaluating the efficacy of photodynamic therapy for symptomatic circumscribed choroidal hemangioma. Ophthalmology 116: 100-105, 2009.

16. Costa RA, Farah ME, Freymüller E, Morales PH, Smith R and Cardillo JA: Choriocapillaris photodynamic therapy using indocyanine green. Am J Ophthalmol 132: 557-565, 2001.

17. Navajas EV, Costa RA, Farah ME, Cardillo JA and Bonomo PP: Indocyanine green-mediated photothrombosis combined with intravitreal triamcinolone for the treatment of choroidal neovascularization in serpiginous choroiditis. Eye (Lond) 17: 563-566, 2003.

18. Arevalo JF, Garcia RA and Mendoza AJ: Indocyanine green-mediated photothrombosis with intravitreal triamcinolone acetonide for subfoveal choroidal neovascularization in age-related macular degeneration. Graefes Arch Clin Exp Ophthalmol 243: 1180-1185, 2005.

19. Arevalo JF, Sanchez JG, Garcia RA, Wu L, Berrocal MH, Rodriguez FJ, Rodríguez A, Novoa LA and Garcia-Amaris R: Indocyanine-green-mediated photothrombosis (IMP) with intravitreal triamcinolone acetonide for macular edema secondary to group 2A idiopathic parafoveal telangiectasis without choroidal neovascularization: A pilot study. Graefes Arch Clin Exp Ophthalmol 245: 1673-1680, 2007.
20. Chappelow AV, Tan K, Waheed NK and Kaiser PK: Panretinal photocoagulation for proliferative diabetic retinopathy: Pattern scan laser versus argon laser. Am J Ophthalmol 153: 137-142, 2012.

21. Mamoon AM, Gamal-Eldeen AM, Ruppel ME, Smith RJ, Tsang T and Miller LM: In vitro efficiency and mechanistic role of indocyanine green as photodynamic therapy agent for human melanoma. Photodiagn Photodyn Ther 6: 105-116, 2009.

22. Adhi M, Alwassia AA and Duker JS: Analysis of choroidal thickness in eyes treated with focal laser photocoagulation using SD-OCT. Can J Ophthalmol 48: 535-538, 2013.

This work is licensed under a Creative Commons Attribution-NonCommercial-NoDerivatives 4.0 International (CC BY-NC-ND 4.0) License. 